\title{
The hormonal profile of benign breast disease
}

\author{
E Samoli ${ }^{1}$, D Trichopoulos ${ }^{2,3}$, A Lagiou ${ }^{4}$, P Zourna ${ }^{1}$, C Georgila ${ }^{1}$, P Minaki ${ }^{1}$, A Barbouni ${ }^{3,5}$, D Vassilarou ${ }^{6}$, \\ A Tsikkinis ${ }^{7}$, C Sfikas ${ }^{8}$, E Spanos ${ }^{9}$ and P Lagiou ${ }^{*, 1,2,3}$ \\ ${ }^{1}$ Department of Hygiene, Epidemiology and Medical Statistics, University of Athens Medical School, 75 M. Asias Street, Goudi GR- \\ 115 27, Greece; ${ }^{2}$ Department of Epidemiology, Harvard School of Public Health, 677 Huntington Avenue, Boston, MA 02115, USA; \\ ${ }^{3}$ Bureau of Epidemiologic Research, Academy of Athens, 28 Panepistimiou Street, Athens GR-106 79, Greece; ${ }^{4}$ Faculty of Health \\ Professions, Athens Technological Educational Institute, 274 Thivon Avenue, Athens GR-12241, Greece; ${ }^{5}$ Department of Public \\ and Administrative Health, National School of Public Health, 196 Alexandras Avenue, Athens GR-115 21, Greece; 'Prolipsis' \\ Diagnostic Center, 85A Mihalakopoulou Street, Athens 11528, Greece; ${ }^{7}$ First Department of Surgery, Elena Venizelou Hospital, 2 \\ Elena Venizelou square, Athens 11521, Greece; ${ }^{8}$ Department of Pathology, Elena Venizelou Hospital, 2 Elena Venizelou Square, \\ Athens 11521, Greece and 'Biomedicine' Diagnostic Center, 132 Kifissias Avenue and Papada Street, Ampelokipi, Athens 11526 , \\ Greece
}

Background: Limited information exists about the endocrine milieu of benign breast disease (BBD), a documented breast cancer risk factor. We compared blood levels of estrogens, testosterone and insulin-like growth factor-1 (IGF-1) between BBD patients by histological type and women without breast pathology.

Methods: We studied 578 BBD patients and 178 healthy women in Athens, Greece, who provided blood samples, and completed interviewer-administered questionnaires.

Results: Of the BBD patients, 254 had non-proliferative disease, 268 proliferative disease without atypia and 56 atypical hyperplasia. Comparing BBD patients with healthy women, the per cent differences (and $95 \%$ confidence intervals) for blood hormones, among pre-menopausal and peri/post-menopausal women, respectively, were: $22.4 \%(-4.0 \%, 56.1 \%)$ and $32.0 \%(5.6 \%$, $65.1 \%)$ for estradiol; $26.2 \%(10.1 \%, 44.8 \%)$ and $30.9 \%(16.8 \%, 46.6 \%)$ for estrone; $19.5 \%(3.1 \%, 38.4 \%)$ and $16.5 \%(-5.0 \%, 42.9 \%)$ for testosterone; and $-5.2 \%(-13.8 \%, 4.4 \%)$ and $-12.1 \%(-19.8 \%,-3.6 \%)$ for IGF-1. Steroid hormones tended to be higher in proliferative compared with non-proliferative BBD.

Conclusions: Circulating steroid hormones tend to be higher among women with BBD than women with no breast pathology and higher in proliferative than non-proliferative disease; these patterns are more evident among peri/post-menopausal women. In peri/post-menopausal women IGF-1 was lower among women with BBD compared with healthy women.

Benign breast disease (BBD) is among the best documented risk factors for breast cancer (Hankinson et al, 2008). According to a large cohort study (Hartmann et al, 2005), the results of which are in line with those of other major investigations (Dupont and Page, 1985, and others reviewed in Pearlman and Griffin, 2010), the risk for breast cancer of women with BBD in comparison with women without $\mathrm{BBD}$ is about 30\% higher for non-proliferative lesions, about two times higher for proliferative lesions without atypia and four times higher for proliferative lesions with atypia. However, although for breast cancer there is a wealth of information about its hormonal profile, indicating positive associations with estrogens and testosterone mainly among post-menopausal women (Key et al, 2002; Eliassen et al, 2006; James et al, 2011), and insulin-like growth factor-1(IGF-1) among both pre- and post-menopausal women (Endogenous Hormones and Breast Cancer Collaborative Group, 2010), there is inconsistent information about the endocrine milieu in $\mathrm{BBD}$, particularly in relation to the main histological types of this condition.

\footnotetext{
*Correspondence: Dr P Lagiou, E-mail: pdlagiou@med.uoa.gr
}

Received 25 June 2012; revised 27 September 2012; accepted 13 October 2012; published online 20 November 2012 
We have undertaken a study in Greece to ascertain levels of circulating estrogens, testosterone and IGF-1 among women with $\mathrm{BBD}$ in comparison with women with no breast pathology.

\section{MATERIALS AND METHODS}

Subjects. From March 2001 to May 2005, women who had undergone mammary biopsy with a diagnosis of BBD in two major breast clinics in Athens, Greece, were asked to participate in the study. There is no organised screening for breast cancer in Greece and it is the women who decide, either on their own or following the advice of their primary care physician, whether, when and where to have a breast examination and mammography; most of these women have had a mammogram before biopsy. In breast clinic I, women who underwent a breast biopsy during the duration of the study or had undergone a biopsy up to 4 years before the study initiation (but were interviewed and, simultaneously, have provided a blood sample during the study period), were included. All women in breast clinic II underwent biopsy during the study period. Tissue samples and the pathology reports were reviewed for accurate diagnostic classification, blindly as to the results of the hormone determinations. Also invited were women who visited the breast clinics but were considered as healthy and did not require a breast biopsy; these women were, as they should be, considered part of the proper study base. Those who agreed to join the study provided informed consent for an in-person interview, review of their medical records and use of biological specimens for research purposes. The study was approved by the Bioethics Committee of the University of Athens.

Among eligible women in both the clinics, we estimate that about $75 \%$ agreed to participate in the study (in several instances, women refused to allow any recording of information concerning agreement to participate in the study; thus, the refusal proportion cannot be accurately calculated). In total 704 women with BBD and 244 healthy women were enrolled in the study.

All women completed an extensive interviewer-administered questionnaire with information on socio-demographic and lifestyle factors, as well as on gynaecological history, general medical history and dietary habits. In breast clinic I, histological samples were available in the form of paraffin-embedded tissue blocks, whereas in breast clinic II, samples obtained during biopsy were frozen in liquid nitrogen before being stored in $-80^{\circ} \mathrm{C}$. For the analysis we excluded 126 women with $\mathrm{BBD}$ and 66 healthy women that had ever used exogenous hormones (mainly oral contraceptives for pre-menopausal women and hormone replacement therapy for peri/post-menopausal women).

Hormone measurements. Blood samples for hormone measurements were collected, at the time of the in-person interview, into sterile tubes, were centrifuged, and then aliquoted and stored for hormonal assays at $-80{ }^{\circ} \mathrm{C}$ at the Department of Hygiene, Epidemiology and Medical Statistics, Medical School, University of Athens. Hormonal analyses were done in the 'Biomedicine' laboratories, blinded as to the case/control status of the subjects. 'Biomedicine' is the only medical diagnostic laboratory in Greece, and one of the few throughout Europe, which has been accredited with an ISO 15189 for a wide range of analyses.

Estradiol-17b and sex hormone-binding globulin (SHBG) were measured with an electrochemiluminescence immunoassay (ECLIA, Elecsys Estradiol II kit, Roche, Mannheim, Germany), with inter- and intra-assay coefficients of variation (CVs at median levels) of $2.5 \%$ and $1.7 \%$ for estradiol, and $2.8 \%$ and $2.4 \%$ for SHBG, respectively. Estrone was measured with a radioimmunoassay (Estrone RIA DSL-8700 kit, Diagnostic Systems Laboratories, Prague, Czech Republic), with inter- and intra-assay CVs (at median levels) of $10.2 \%$ and $9.4 \%$, respectively. Testosterone was measured by a method similar to estradiol using an ECLIA (Elecsys Testosterone kit for Elecsys 1010/2010, Roche), with interand intra-assay CVs (at median levels) of $2.8 \%$ and $1.8 \%$, respectively. Insulin-like growth factor-1 and IGF-binding protein 3 (IGFBP-3) were measured by chemical luminescence immunoassay kits (Immulite 2500 kit, Diagnostic Products Corporation, Siemens, Llanberis Gwynedd, UK). The inter-assay and intra-assay CVs (at median levels) were $7.4 \%$ and $2.9 \%$ for IGF-1, and $6.8 \%$ and $4.2 \%$ for IGFBP-3, respectively. Electrochemiluminescence immunoassay is the most advanced routine method available for hormones determinations. The CVs reported are internal laboratory results.

Statistical analysis. The statistical analyses were conducted using the SPSS statistical package (IBM Statistical Package for Social Sciences v. 19.0, Chicago, IL, USA). At first, we distributed BBD cases with non-proliferative disease, BBD cases with proliferative disease, $\mathrm{BBD}$ cases with atypical hyperplasia and healthy women by demographic and gynaecological characteristics (specified in the relevant Table), as well as levels of the studied endocrine compounds (median, 10th and 90th percentile for each hormone and each breast disease category). Owing to the influence of the menopausal status (ascertained at the time of the interview and blood collection) on hormonal levels, the analysis was further stratified by pre- and peri/post-menopausal status. Finally, we used multiple regression to compare log-transformed serum hormone levels between women with BBD and healthy women, as well as, among women with $\mathrm{BBD}$, between those with proliferative $\mathrm{BBD}$ (with or without atypia) and those with non-proliferative BBD. In all models we controlled for age (initially categorically, but finally more finely as continuous variable), while in the analysis of premenopausal women we further controlled for day of the cycle (as an indicator variable with $1=$ blood sample collected between 2 nd and 11 th day and $0=$ else). In additional analyses we have also controlled for age at menarche, parity and body mass index (BMI). In the models of estradiol, estrone and testosterone we also controlled for SHBG (as continuous variable).

\section{RESULTS}

We have examined the hormonal profile of 578 women with BBD in comparison with 178 apparently healthy women. From the 578 women with BBD and no previous exogenous hormone use, 254 had non-proliferative disease, 268 had proliferative disease without atypia whereas 56 had atypical hyperplasia. In Table 1, the distribution of all women by diagnostic category and demographic and reproductive characteristics is shown. In comparison with healthy control women, those with BBD tended to be younger (71.3\% vs $34.8 \%$ were below 50 years) and more frequently premenopausal (67.8\% vs 31.5\%). There were no striking differences between the two groups with respect to age at menarche or age at menopause, nor with respect to lifestyle variables. These data, however, serve only descriptive purposes and are not directly interpretable because of the inter-correlations among the classification variables in this Table.

In Table 2, the median, as well as the 10th and 90th percentile of each of the measured hormones by diagnosis and menopausal status, are shown. Estrogens, and to a lesser extent testosterone and IGF-1, are higher among pre-menopausal than among peri- and post-menopausal women. There is an indication that levels of steroid hormones are higher among women with BBD than among healthy women, both among pre- and peri/post-menopausal women. With respect to IGF-1 the opposite appears to be true, particularly among peri- and post-menopausal women. These data, however, are not adjusted for age and, among pre-menopausal women, for day of the cycle. 
Table 1. Distribution (number (\%)) of women by diagnosis and demographic and reproductive characteristics

\begin{tabular}{|c|c|c|c|c|c|}
\hline & $\begin{array}{l}\text { Healthy } \\
(n=178)\end{array}$ & $\begin{array}{l}\text { BBD non-proliferative } \\
(n=254)\end{array}$ & $\begin{array}{l}\text { BBD proliferative with no atypia } \\
\qquad(n=268)\end{array}$ & $\begin{array}{l}\text { BBD atypical hyperplasia } \\
\qquad(n=56)\end{array}$ & $\begin{array}{l}\text { All BBD } \\
(n=578)\end{array}$ \\
\hline \multicolumn{6}{|c|}{ Age (years) } \\
\hline $50-59$ & $68(38.2)$ & $38(15.0)$ & $36(13.4)$ & $15(26.8)$ & $89(15.4)$ \\
\hline $60+$ & $48(27.0)$ & $30(11.8)$ & $37(13.8)$ & $10(17.9)$ & $77(13.3)$ \\
\hline Pre & $56(31.5)$ & $178(70.1)$ & $182(67.9)$ & $32(57.1)$ & $392(67.8)$ \\
\hline $\begin{array}{l}\text { Peri and } \\
\text { post }\end{array}$ & $122(68.5)$ & $76(29.9)$ & $86(32.1)$ & $24(42.9)$ & $186(32.2)$ \\
\hline \multicolumn{6}{|c|}{ Age at menarche (years) } \\
\hline-12 & $72(40.7)$ & $103(41.0)$ & $101(38.1)$ & $25(44.6)$ & $229(40.0)$ \\
\hline-44 & $20(16.4)$ & $19(25.0)$ & $13(15.1)$ & $3(12.5)$ & $35(18.8)$ \\
\hline $45-49$ & $37(30.3)$ & $17(22.4)$ & $27(31.4)$ & $7(29.2)$ & $51(27.4)$ \\
\hline $50-54$ & $54(44.3)$ & $32(42.1)$ & $39(45.3)$ & $13(54.2)$ & $84(45.2)$ \\
\hline $55+$ & $11(9.0)$ & $8(10.5)$ & $7(8.1)$ & $1(4.2)$ & $16(8.6)$ \\
\hline \multicolumn{6}{|l|}{ Parous } \\
\hline Yes & $156(87.6)$ & $167(65.7)$ & $182(67.9)$ & $50(89.3)$ & $399(69.0)$ \\
\hline No & $22(12.4)$ & $87(34.3)$ & $86(32.1)$ & $6(10.7)$ & $179(31.0)$ \\
\hline \multicolumn{6}{|c|}{ BMI $\left(\mathrm{kg} \mathrm{m}^{-2}\right)$} \\
\hline-25 & $69(38.8)$ & $138(54.3)$ & $146(54.9)$ & $24(42.9)$ & $308(53.5)$ \\
\hline $26-29.99$ & $61(34.3)$ & $68(26.8)$ & $72(27.1)$ & $16(28.6)$ & $156(27.1)$ \\
\hline-6 & $43(24.2)$ & $52(20.5)$ & $42(15.7)$ & $15(26.8)$ & $109(18.9)$ \\
\hline $7-12$ & $81(45.5)$ & $99(39.0)$ & $125(46.8)$ & $21(37.5)$ & $245(42.5)$ \\
\hline $13+$ & $54(30.3)$ & $103(40.6)$ & $100(37.5)$ & $20(35.7)$ & $223(38.6)$ \\
\hline \multicolumn{6}{|c|}{ Lactation (among parous) } \\
\hline Yes & $128(82.1)$ & $141(84.4)$ & $157(86.3)$ & 41 (82.0) & $339(85.0)$ \\
\hline No & $28(17.9)$ & $26(15.6)$ & $25(13.7)$ & $9(18.0)$ & $60(15.0)$ \\
\hline
\end{tabular}

In Table 3, the log-transformed levels of the measured hormones are compared, firstly between women with BBD and healthy women and, secondly, between women with proliferative BBD disease (with or without atypia) and women with non-proliferative BBD. There is strong evidence that steroid hormones, particularly estrogens, are higher among women with BBD than among healthy women, and the contrasts appear sharper among peri/post-menopausal women. Thus, among pre-menopausal women estradiol, estrone and testosterone are higher by $22.4 \%(P=0.105), 26.2 \%(P=0.001)$ and $19.5 \%(P=0.018)$, respectively, whereas among peri/postmenopausal the corresponding differences are $32.0 \%(P=0.015)$, $30.9 \%(P<0.001)$ and $16.5 \%(P=0.141)$, respectively. A similar pattern is evident when women with proliferative BBD are compared with those with non-proliferative $\mathrm{BBD}$, and again the contrasts appear sharper among peri/post-menopausal women. Thus, among pre-menopausal women estradiol and estrone are higher by $11.7 \%$ $(P=0.201)$ and $10.0 \%(P=0.054)$, respectively, whereas among peri/post-menopausal the corresponding differences are $31.9 \%$ $(P=0.072)$ and $24.7 \%(P=0.008)$, respectively; no differences were evident in these comparisons with respect to testosterone.

With respect to IGF-1 and IGFBP-3, levels are lower among women with $\mathrm{BBD}$ in comparison with healthy women and the differences are statistically significant among peri/post-menopausal women. Thus, among pre-menopausal women IGF-1 and IGFBP-3 are lower by $5.2 \%(P=0.287)$ and $4.3 \%(P=0.132)$, respectively, whereas among peri/post-menopausal the corresponding differences are $12.1 \%(P=0.006)$ and $7.7 \%(P=0.008)$, respectively. Mutual adjustment between IGF-1 and IGFBP-3, however, led to a reduction of the absolute values of the respective regression coefficients. When women with proliferative $\mathrm{BBD}$ are contrasted to 
Table 2. Median (10th-90th percentile) of measured hormones by diagnosis and menopausal status

\begin{tabular}{|c|c|c|c|c|c|}
\hline & Healthy & $\begin{array}{l}\text { BBD non- } \\
\text { proliferative }\end{array}$ & $\begin{array}{l}\text { BBD proliferative with no } \\
\text { atypia }\end{array}$ & $\begin{array}{l}\text { BBD atypical } \\
\text { hyperplasia }\end{array}$ & All BBD \\
\hline Pre-menopausal women & $\mathrm{n}=56$ & $\mathrm{n}=178$ & $\mathrm{n}=182$ & $\mathrm{n}=32$ & $n=392$ \\
\hline $\begin{array}{l}\text { Estradiol }\left(\mathrm{pg} \mathrm{ml}^{-1}\right) \\
\text { Estrone }\left(\mathrm{pg} \mathrm{ml}^{-1}\right. \\
\text { Testosterone }\left(\mathrm{ng} \mathrm{dl}^{-1}\right) \\
\text { SHBG }\left(\mathrm{nmoll}^{-1}\right) \\
\text { IGF-1 }\left(\mathrm{ng} \mathrm{ml} l^{-1}\right) \\
\text { IGFBP-3 }\left(\mu \mathrm{g} \mathrm{ml}^{-1}\right)\end{array}$ & $\begin{aligned} & 68.0(27.7-321.0) \\
& 52.8(32.7-113.8) \\
& 29.5(12.7-55.6) \\
& 56.0(31.4-114.4) \\
& 171.5(98.7-242.3) \\
& 4.0(3.1-5.5)\end{aligned}$ & $\begin{array}{c}97.5(28.0-291.9) \\
65.1(38.0-129.5) \\
38.5(18.0-71.0) \\
64.0(32.0-115.3) \\
169.0(110.0-283.0) \\
4.0(3.1-5.1)\end{array}$ & $\begin{array}{c}108.0(36.3-277.4) \\
71.5(41.6-145.7) \\
40.0(17.0-67.0) \\
65.3(30.3-114.0) \\
175.0(104.6-290.3) \\
4.0(3.1-5.1)\end{array}$ & $\begin{aligned} 116.5 & (25.9-568.6) \\
65.5 & (37.4-137.0) \\
30.0 & (12.6-57.2) \\
57.5 & (33.7-124.5) \\
153.0 & (104.6-235.9) \\
3.8 & (3.0-5.4)\end{aligned}$ & $\begin{array}{c}104.0(32.2-299.4) \\
67.0(39.0-140.0) \\
38.0(17.0-67.7) \\
64.0(31.7-115.0) \\
169.0(11.0-276.7) \\
4.0(3.1-5.1)\end{array}$ \\
\hline $\begin{array}{l}\text { Peri/post-menopausal } \\
\text { women }\end{array}$ & $\mathrm{n}=122$ & $n=76$ & $n=86$ & $n=24$ & $\mathrm{n}=186$ \\
\hline $\begin{array}{l}\text { Estradiol }\left(\mathrm{pg} \mathrm{ml}^{-1}\right) \\
\text { Estrone }\left(\mathrm{pg} \mathrm{ml}^{-1}\right) \\
\text { Testosterone }\left(\mathrm{ng} \mathrm{dl}^{-1}\right) \\
\text { SHBG }\left(\mathrm{nmoll}^{-1}\right) \\
\text { IGF-1 }\left(\mathrm{ng} \mathrm{ml}^{-1}\right) \\
\text { IGFBP-3 }\left(\mu \mathrm{g} \mathrm{ml}^{-1}\right)\end{array}$ & $\begin{array}{c}11.0(5.0-25.0) \\
29.3(19.5-46.1) \\
20.0(6.0-40.0) \\
52.5(31.3-97.1) \\
133.0(76.6-203.1) \\
3.9(2.8-5.4)\end{array}$ & $\begin{array}{c}11.0(5.0-100.8) \\
33.8(20.0-72.3) \\
19.5(5.7-50.3) \\
58.5(32.7-117.7) \\
127.5(70.0-186.9) \\
3.7(2.8-4.7)\end{array}$ & $\begin{aligned} & 14.0 \\
& 41.9(21.0-161.8) \\
& 22.0(6.7-46.3) \\
& 51.5(26.1-114.0) \\
& 110.0(56.1-166.6) \\
& 3.8(2.2-5.2)\end{aligned}$ & $\begin{array}{c}11.0(5.0-86.5) \\
35.5(23.5-74.6) \\
24.0(10.5-56.0) \\
60.5(32.5-103.0) \\
112.0(78.5-165.0) \\
3.6(2.8-5.1)\end{array}$ & $\begin{array}{c}12.5(5.0-117.9) \\
36.0(21.0-91.4) \\
22.0(7.0-47.3) \\
55.0(29.0-112.6) \\
112.0(66.0-175.0) \\
3.7(2.6-5.1)\end{array}$ \\
\hline
\end{tabular}

Abbreviations: BBD = benign breast disease; IGF-1 = insulin-like growth factor 1; IGFBP-3=IGF-binding protein 3; SHBG = sex hormone-binding globulin.

Table 3. Percent difference (and 95\% Cls) of the measured hormones for BBD vs healthy women, as well as among women with BBD, for proliferative vs non-proliferative BBD

\begin{tabular}{|c|c|c|c|c|c|c|c|c|}
\hline & \multicolumn{4}{|c|}{ Pre-menopausal women } & \multicolumn{4}{|c|}{ Peri/post-menopausal women } \\
\hline & \multicolumn{2}{|l|}{$\begin{array}{l}\text { BBD }(n=392) \\
\text { vs healthy } \\
(n=56)\end{array}$} & \multicolumn{2}{|c|}{$\begin{array}{l}\text { Proliferative }(n=214) \\
\text { vs non-proliferative } \\
(n=178) \text { BBD }\end{array}$} & \multicolumn{2}{|l|}{$\begin{array}{c}\text { BBD }(n=186) \\
\text { vs healthy } \\
(n=122)\end{array}$} & \multicolumn{2}{|c|}{$\begin{array}{l}\text { Proliferative }(n=110) \\
\text { vs non-proliferative } \\
(n=76) \text { BBD }\end{array}$} \\
\hline & $\begin{array}{c}\text { Percentage } \\
\text { increase }(95 \% \mathrm{Cl})\end{array}$ & $\begin{array}{c}P \text { - } \\
\text { value }\end{array}$ & $\begin{array}{c}\text { Percentage } \\
\text { increase }(95 \% \mathrm{Cl})\end{array}$ & $\begin{array}{c}P \text { - } \\
\text { value }\end{array}$ & $\begin{array}{c}\text { Percentage increase } \\
(95 \% \mathrm{Cl})\end{array}$ & $\begin{array}{c}P \text { - } \\
\text { value }\end{array}$ & $\begin{array}{c}\text { Percentage increase } \\
(95 \% \mathrm{Cl})\end{array}$ & $\begin{array}{r}P \text { - } \\
\text { value }\end{array}$ \\
\hline Estradiol $^{\mathbf{b}}$ & $22.4(-4.0$ to 56.1$)$ & 0.105 & $11.7(-5.8$ to 32.5$)$ & 0.201 & $32.0(5.6$ to 65.1$)$ & 0.015 & $31.9(-2.3$ to 78.0$)$ & 0.072 \\
\hline Estrone $^{\mathbf{b}}$ & $26.2(10.1$ to 44.8$)$ & 0.001 & $10.0(-0.1$ to 21.1$)$ & 0.054 & $30.9(16.8$ to 46.6$)$ & $<0.001$ & 24.7 (6.2 to 46.5$)$ & 0.008 \\
\hline Testoterone $^{\mathbf{b}}$ & 19.5 (3.1 to 38.4$)$ & 0.018 & $-0.1(-9.8$ to 10.6$)$ & 0.991 & $16.5(-5.0$ to 42.9$)$ & 0.141 & $5.9(-17.8$ to 36.3$)$ & 0.659 \\
\hline SHBG & $8.9(-5.3$ to 25.1$)$ & 0.233 & $-0.9(-10.3$ to 9.5$)$ & 0.855 & $3.8(-7.6$ to 16.5$)$ & 0.529 & $-13.1(-25.4$ to 1.3$)$ & 0.074 \\
\hline IGF-1 & $-5.2(-13.8$ to 4.4$)$ & 0.287 & $5.5(-1.4$ to 13.0$)$ & 0.120 & $-12.1(-19.8$ to -3.6$)$ & 0.006 & $-7.6(-18.3$ to 4.5$)$ & 0.207 \\
\hline IGFBP-3 & $-4.3(-9.6$ to 1.3$)$ & 0.132 & $0.8(-2.9$ to 4.6$)$ & 0.666 & $-7.7(-13.0$ to -2.1$)$ & 0.008 & $-1.1(-8.7$ to 7.2$)$ & 0.781 \\
\hline ac contolline & Fint & & & & & & & \\
\hline
\end{tabular}

those with non-proliferative $\mathrm{BBD}$, the patterns are inconsistent (Table 3).

In additional analyses, we also controlled for age at menarche, parity and BMI, always separately for pre-menopausal and peri/postmenopausal women, and the results were essentially unchanged (only with respect to estrone, when comparing proliferative to nonproliferative $\mathrm{BBD}$ among pre-menopausal women the per cent difference increased from 10.0 to 11.2 and the $P$-value from 0.054 became significant at 0.040 ). We have also repeated the analyses after exclusion of women from breast clinic I who were biopsied before they were contacted, but were interviewed and provided blood samples during the undertaking of the present study; the results were consistent apart from random variation.

\section{DISCUSSION}

In a large case-control study, comparing 578 women with BBD who had never used exogenous hormones (254 with non- proliferative disease, 268 with proliferative disease without atypia and 56 with proliferative disease and atypia) with 178 women without $\mathrm{BBD}$ who also had never used exogenous hormones, we have found evidence that steroid hormones, particularly estrogens, are higher among women with BBD than among healthy women and higher among women with proliferative BBD than among those with non-proliferative disease. We also found evidence that IGF-1 and IGFBP-3 tend to be lower among women with BBD in comparison with healthy women. All the indicated patterns were clearer among peri/post-menopausal women than among premenopausal ones.

The hormonal profile of BBD has generally been investigated in case-control or cross-sectional studies, frequently of modest sample size, and the results are not consistent. A few studies, including an experimental study in ovariectomised female nude mice (Shekhar et al, 1998) and a case-control study among 184 women with BBD and 50 apparently healthy women (Sitruk-Ware et al, 1979), have suggested that estrogens may be increased in BBD. Several reports, however, from early case-control studies 
(Reed et al (1983), with $16 \mathrm{BBD}$ cases and 35 control women; Gorins and Cordray (1984), with 171 BBD cases and use of 'background normal' levels; Langley et al (1985), with 47 BBD cases and 71 control women; Ernster et al (1987), with 992 cases and 851 control women but response rates below 50\%; Mancini et al (1991), with 131 women with breast pathology and use of 'background normal' levels; Mancini et al (1992), with 39 women with BBD and unspecified number of control women; Mady (2000), with 40 BBD cases and unspecified number of control women) indicate no increase in estradiol, estrone or testosterone in $\mathrm{BBD}$. With respect to SHBG, a very small case-control study (Parlati et al, 1988) has indicated that it may be increased in BBD, whereas another study generated equivocal results (Mancini et al, 1991, with 131 women with breast pathology and use of 'background normal' levels). Regarding the IGF system, some case-control studies (Enriori et al (2003), with 41 BBD cases and 25 control women; Singer et al (2004), with 23 BBD cases and 38 control women; Barnes et al (2009), with 149 BBD cases and 733 control women) reported that IGF-1 is increased in BBD, a study indicated that in BBD higher levels of IGF-1 reduce the likelihood of lobular involution (Rice et al (2012), a cross-sectional study among 472 women), whereas another case-control study has indicated no association of IGF-1 with proliferative BBD (Su et al (2010), with 359 BBD cases and 359 control women). For IGFBP-3, there have been reports from case-control studies of higher levels in BBD (Holdaway et al (1999), with 12 BBD cases and 43 control women; Su et al (2010), with 359 BBD cases and 359 controls). Thus, there is no clear evidence in the literature concerning the hormonal profile of $\mathrm{BBD}$ and essentially no data about the hormonal profile of the subcategories of BBD.

We interpret our findings as indicating that increased levels of steroid hormones, particularly estrogens, favour the development of $\mathrm{BBD}$ and particularly proliferative $\mathrm{BBD}$. While not related to endogenous hormones, recent observations also support a role for reproductive hormone influence on BBD. In the Women's Health Initiative randomised, placebo-controlled hormone therapy trials, conjugated equine oestrogen resulted in a statistically significant increase in BBD (Rohan et al, 2008).

Taking into account the documented positive association of IGF-1 with breast cancer risk (Endogenous Hormones and Breast Cancer Collaborative Group, 2010), the increased risk for breast cancer among women with $\mathrm{BBD}$, particularly proliferative $\mathrm{BBD}$ with atypia (Hartmann et al, 2005) and the apparent tendency of BBD patients to have lower levels of IGF-1 compared with healthy controls notably among peri/post-menopausal women (Table 3), we hypothesise that higher IGF-1 levels could have a crucial role in promoting the malignant transformation in BBD tissue. In essence we postulate that lower IGF-1 levels in BBD patients hinder progression to breast cancer in this high risk group, although this finding needs to be replicated in other large investigations.

Strengths of this investigation are the adequate sample size (in fact, to our knowledge, among modern investigations, our study has the largest series of BBD cases), the use of state of the art assays for hormone determinations and the use of a comparison group of healthy women from the same study base. The study was not restricted to newly diagnosed BBD cases, as some of the women in breast clinic I had their biopsies before their blood collection, but this is unlikely to have affected the hormone measurements, as medication is generally not prescribed for BBD and menopausal status of these women was assessed at blood draw. A general assumption in epidemiological studies evaluating the hormonal profile of BBD is that levels ascertained at a certain point in time reflect overall long-term levels, provided that therapy, particularly hormonal therapy, has not intervened. As all studies in this topic, we have no information on hormone at the level of breast tissue.

In conclusion, we have found evidence that levels of estradiol, estrone and testosterone tend to be higher among women with
BBD compared with women with no breast pathology. Among women with $\mathrm{BBD}$, the levels of these hormones tend to be higher in those with proliferative compared with non-proliferative BBD. With respect to levels of IGF-1 and IGFBP-3, they tend to be lower among women with BBD rather than women with no breast pathology and the contrast is more evident among peri/postmenopausal women.

\section{ACKNOWLEDGEMENTS}

This study was partially supported by: the National Institutes of Health/National Cancer Institute, USA (CA89823); the European Union - European Social Fund and Greek Ministry of Development - General Secretariat for Research and Technology (03ED44 PENED project); the Academy of Athens and the University of Athens, Greece (Kapodistrias Program).

\section{REFERENCES}

Barnes BB, Chang-Claude J, Flesch-Janys D, Kinscherf R, Schmidt M, Slanger T, Bonaterra G, Steindorf K (2009) Cancer risk factors associated with insulin-like growth factor (IGF)-I and IGF-binding protein-3 levels in healthy women: effect modification by menopausal status. Cancer Causes Control 20: 1985-1996.

Dupont WD, Page DL (1985) Risk factors for breast cancer in women with proliferative breast disease. N Engl J Med 312: 146-151.

Eliassen AH, Missmer SA, Tworoger SS, Spiegelman D, Barbieri RL, Dowsett M, Hankinson SE (2006) Endogenous steroid hormone concentrations and risk of breast cancer among premenopausal women. J Natl Cancer Inst 98: 1406-1415.

Endogenous Hormones and Breast Cancer Collaborative Group, Key TJ, Appleby PN, Reeves GK, Roddam AW (2010) Insulin-like growth factor 1 (IGF1), IGF binding protein 3 (IGFBP3), and breast cancer risk: pooled individual data analysis of 17 prospective studies. Lancet Oncol 11: 530-542.

Enriori PJ, Fischer CR, Gori JR, Etkin AE, Calandra RS, Lüthy IA (2003) Augmented serum levels of the IGF-I/IGF-binding protein-3 ratio in pre-menopausal patients with type I breast cysts. Eur J Endocrinol 148: $177-184$.

Ernster VL, Wrensch MR, Petrakis NL, King EB, Miike R, Murai J, Goodson 3rd WH, Siiteri PK (1987) Benign and malignant breast disease: initial study results of serum and breast fluid analyses of endogenous estrogens. J Natl Cancer Inst 79: 949-960.

Gorins A, Cordray JP (1984) Hormonal profile of benign breast disease and premenstrual mastodynia. Eur J Gynaecol Oncol 5: 1-10.

Hankinson S, Talamimi R, Hunter D (2008) Breast cancer. In Textbook of Cancer Epidemiology, Adami HO, Hunter D, Trichopoulos D (eds)pp: 403-445. Oxford University Press: Oxford, UK.

Hartmann LC, Sellers TA, Frost MH, Lingle WL, Degnim AC, Ghosh K, Vierkant RA, Maloney SD, Pankratz VS, Hillman DW, Suman VJ, Johnson J, Blake C, Tlsty T, Vachon CM, Melton 3rd LJ, Visscher DW (2005) Benign breast disease and the risk of breast cancer. N Engl J Med 353: 229-237.

Holdaway IM, Mason BH, Lethaby AE, Singh V, Harman JE, MacCormick M, Civil ID (1999) Serum levels of insulin-like growth factor binding protein3 in benign and malignant breast disease. Aust N Z J Surg 69(7): 495-500.

James RE, Lukanova A, Dossus L, Becker S, Rinaldi S, Tjønneland A, Olsen A, Overvad K, Mesrine S, Engel P, Clavel-Chapelon F, Chang-Claude J, Vrieling A, Boeing H, Schütze M, Trichopoulou A, Lagiou P, Trichopoulos D, Palli D, Krogh V, Panico S, Tumino R, Sacerdote C, Rodríguez L, Buckland G, Sánchez MJ, Amiano P, Ardanaz E, Bueno-de-Mesquita B, Ros MM, van Gils CH, Peeters PH, Khaw KT, Wareham N, Key TJ, Allen NE, Romieu I, Siddiq A, Cox D, Riboli E, Kaaks R (2011) Postmenopausal serum sex steroids and risk of hormone receptor-positive and -negative breast cancer: a nested case-control study. Cancer Prev Res (Phila) 4: 1626-1635.

Key T, Appleby P, Barnes I, Reeves G, Endogenous Hormones and Breast Cancer Collaborative Group (2002) Endogenous sex hormones and breast 
cancer in postmenopausal women: reanalysis of nine prospective studies. J Natl Cancer Inst 94: 606-616.

Langley MS, Hammond GL, Bardsley A, Sellwood RA, Anderson DC (1985) Serum steroid binding proteins and the bioavailability of estradiol in relation to breast diseases. J Natl Cancer Inst 75: 823-829.

Mady EA (2000) Association between estradiol, estrogen receptors, total lipids, triglycerides, and cholesterol in patients with benign and malignant breast tumors. J Steroid Biochem Mol Biol 75: 323-328.

Mancini A, Di Pietro C, De Marinis L, Rossi S, Lombardi CP, Bellantone R, Liberale I, Menini E, Crucitti F (1991) Endocrine status in patients with mammary gland diseases: correlation between steroid hormones and sex steroid binding globulin. Gynecol Endocrinol 5: 101-108.

Mancini A, di Pietro C, De Marinis L, Rossi S, Lombardi CP, Iacona T, Bellantone R, Liberale I, Menini E, Crucitti F (1992) Endocrine evaluation of patients with benign lumps of the breast. Cancer Detect Prev 16: $27-30$.

Parlati E, Travaglini A, Liberale I, Menini E, Dell'Acqua S (1988) Hormonal profile in benign breast disease. Endocrine status of cyclical mastalgia patients. J Endocrinol Invest 11: 679-683.

Pearlman MD, Griffin JL (2010) Benign breast disease. Obstet Gynecol 116: $747-758$.

Reed MJ, Cheng RW, Noel CT, Dudley HA, James VH (1983) Plasma levels of estrone, estrone sulfate, and estradiol and the percentage of unbound estradiol in postmenopausal women with and without breast disease. Cancer Res 43: 3940-3943.

Rice MS, Tamimi RM, Connolly JL, Collins LC, Shen D, Pollak MN, Rosner B, Hankinson SE, Tworoger SS (2012) Insulin-like growth factor-1, insulin- like growth factor binding protein-3 and lobule type in the Nurses' Health Study II. Breast Cancer Res 14: R44.

Rohan TE, Negassa A, Chlebowski RT, Habel L, McTiernan A, Ginsberg M, Wassertheil-Smoller S, Page DL (2008) Conjugated equine estrogen and risk of benign proliferative breast disease: a randomized controlled trial. J Natl Cancer Inst 100: 563-571.

Shekhar MP, Nangia-Makker P, Wolman SR, Tait L, Heppner GH, Visscher DW (1998) Direct action of estrogen on sequence of progression of human preneoplastic breast disease. Am J Pathol 152: 1129-1132.

Singer CF, Mogg M, Koestler W, Pacher M, Marton E, Kubista E, Schreiber M (2004) Insulin-like growth factor (IGF)-I and IGF-II serum concentrations in patients with benign and malignant breast lesions: free IGF-II is correlated with breast cancer size. Clin Cancer Res 10: 4003-4009.

Sitruk-Ware R, Sterkers N, Mauvais-Jarvis P (1979) Benign breast disease I: hormonal investigation. Obstet Gynecol 53: 457-460.

Su X, Colditz GA, Willett WC, Collins LC, Schnitt SJ, Connolly JL, Pollak MN, Rosner B, Tamimi RM (2010) Genetic variation and circulating levels of IGF-I and IGFBP-3 in relation to risk of proliferative benign breast disease. Int J Cancer 126: 180-190.

This work is published under the standard license to publish agreement. After 12 months the work will become freely available and the license terms will switch to a Creative Commons AttributionNonCommercial-Share Alike 3.0 Unported License. 